\title{
QUANDO A MODA É POLÍTICA: AS MULHERES NEGRAS E A REVISTA AFRO BRASIL
}

\section{Resumo}

Neste artigo realizam-se algumas reflexões acerca da mulher negra e sua relação com a moda como ferramenta de luta sociopolítica. Elegemos como campo de estudo a revista Raça Brasil, que teve seu nome alterado em meados do ano de 2016 para Afro Brasil. A partir do periódico e da seleção de alguns de seus exemplares e colunas, abordamos a presença e representação da mulher negra relacionando a mesma aos elementos culturais e políticos presentes na moda. A partir das colunas de moda e beleza, foi possível relacionar a luta do feminismo negro presente na sociedade brasileira através de um discurso de valorização étnico-racial que nos leva a pensar a moda como uma ferramenta de reivindicação social e, portanto, política.

Palavras-chave: Revista Afro Brasil, mulheres negras, moda, feminismo.

\section{Abstract}

When fashion is political: the black women and the Magazine Afro Brasil

This article discusses about black woman and the relationship with fashion as a tool for socio-political struggle. We chose as field of study the magazine Raça Brasil, that had its name changed in the middle of the year 2016 for Afro Brazil. From the periodical and the selection of some of its issues and columns, we address the presence and representation of the black woman relating it to the cultural and political elements present in fashion. From the columns of fashion and beauty, it was possible to relate the struggle of black feminism present in the Brazilian society through a discourse of ethnic-racial valorization that leads us to think of fashion as a tool of social and therefore political claim.

Key words: Magazine Afro Brasil, black women, fashion, feminism.

\section{Resumen}

\section{Cuando la moda es política: las mujeres negras y la Revista Afro Brasil}

En este artículo se realizan algunas reflexiones acerca de la mujer negra y su relación con la moda como herramienta de lucha sociopolítica. Elegimos como campo de estudio la revista Raza Brasil, que tuve su nombre alterado a mediados del año 2016 a Afro Brasil. A partir del periódico y la selección de algunos de sus ejemplares y columnas, abordamos

\footnotetext{
* $\quad$ Universidade Feevale, CEP 93510.335 Novo Hamburgo, RS, Brasil.

Endereço postal: Av. Mauricio Cardoso, 1429 apto. 902 CEP 93510.335 Novo Hamburgo, RS, Brasil. Endereço eletrónico: 1.adamsbraga@gmail.com

** Universidade Feevale, CEP 93510.335 Novo Hamburgo, RS, Brasil.

Endereço eletrónico: magna@feevale.br

*** Universidade Feevale, CEP 93510.335 Novo Hamburgo, RS, Brasil.

Endereço eletrónico: claudias@feevale.br
} 
la presencia y representación de la mujer negra relacionándola a los elementos culturales y políticos presentes en la moda. A partir de las columnas de moda y belleza, fue posible relacionar la lucha del feminismo negro presente en la sociedad brasileña a través de un discurso de valoración étnico-racial que nos lleva a pensar la moda como una herramienta de reivindicación social y, por lo tanto, política.

Palabras clave: Revista Afro Brasil, mujeres negras, moda, feminismo.

\section{Introdução}

Sabemos que as mulheres brasileiras são diversas, posto que somos um país multirracial desde a sua formação. No entanto, ainda estamos presos a uma padronização no que tange às representações da beleza feminina. O que estamos falando aqui não é nenhuma novidade, pois um olhar mais atento para as campanhas publicitárias, periódicos e teledramaturgia é o suficiente para constatarmos que há uma norma de beleza vigente: mulheres brancas, magras, heterossexuais e jovens. O que isso acarreta, em uma sociedade desigual, é preocupante para todos aqueles que discutem e defendem a valorização e o respeito pela diversidade e pelos Direitos Humanos.

A partir deste cenário, consideramos relevante pensar acerca das mulheres negras, ${ }^{1}$ pois o facto de elas não aparecerem - ou aparecerem pouco e estereotipadas - na mídia é uma das tantas maneiras de inviabilizá-las na nossa sociedade.

No presente artigo, pretende-se refletir sobre como a moda, sendo uma manifestação cultural, tem o poder de quebra de silêncio e de visibilização, pois o corpo e as vestes estão em constante diálogo com o meio social. A moda fala e, nesse caso, tem falado em alto e em bom som sobre a importância e a presença das mulheres negras em meio à formação sociocultural e política do Brasil.

Oliveira (2011) informa que, no Brasil, mesmo com a presença significativa da população negra e sua forte influência cultural e nas decisões de consumo, pouco se pesquisa a seu respeito em relação à dinâmica mercadológica e o comportamento dos consumidores. Para a autora, o consumo para a população negra pode ressignificar suas representações culturais, já que expressam ascensão social de uma população comumente de baixa renda e pode ser uma estratégia para amenizar os efeitos da discriminação.

\footnotetext{
Os termos negra e negro estão sendo pensados a partir da perspectiva de ressignificação e de distanciamento da «carga pejorativa que envolvia a terminologia». A ressignificação do termo está em meio ao contexto de lutas e resistências dos movimentos negros contra o racismo e a exclusão social. Concomitante ao debate e lutas de afirmação de identidades étnicas, também o termo afro-brasileiro, afro-americanos e afrodescendentes ganham relevância e se tornam realidades denunciadoras dos processos de exclusões, ao mesmo tempo referência para se propor e buscar estratégias conjuntas de inclusão (Rocha 2010, 899-907).
} 
Neste sentido, discutir sobre o tema elencado neste artigo passa por pensar um contexto socio-histórico permeado por hierarquias e relações de poder que se constituem em um sistema socioeconômico de exploração e exclusão racial que se «naturaliza» principalmente a partir de significantes corporais como cor da pele, características físicas do cabelo, as feições do rosto, entre outros (Hall 2003, 70).

A revista Afro Brasil é o periódico escolhido por nós para analisar como este grupo de mulheres brasileiras é representado. Este periódico era intitulado Raça Brasil e, no ano de 2016, alterou seu nome. A necessidade de um veículo segmentado para o negro brasileiro foi uma das principais justificativas dos criadores da revista, pois este grupo não tinha espaço nos principais veículos nacionais.

Para este artigo, optamos por trabalhar com os dois últimos exemplares da Raça Brasil e o segundo exemplar da Afro Brasil, edições dos números 197, 198 e 2, que circularam entre o final de 2015 e o início de 2016.

\section{Ser mulher e ser negra}

Os negros, as mulheres e demais grupos considerados minoritários foram negligenciados por muito tempo nas produções historiográficas. Somente em 1960, como pontuam Soihet e Pedro (2007), que o campo histórico voltou seu olhar para grupos antes excluídos, passando então a incluir mulheres, camponeses, operários, escravizados, etc. No entanto, ainda que as mulheres tenham começado a ser alvo de um olhar mais atento por parte de estudiosos, foi apenas por volta de 1970 que o discurso feminista começou a contestar a ideia da homogeneidade sobre mulheres que era, em geral, abordada pelos historiadores.

Firmou-se a ideia de reivindicar a «diferença dentro da diferença», pois as mulheres «não podem ser tratadas, exclusivamente, sob a rubrica da questão de gêneros se esta não levar em conta as especificidades que definem o ser mulher neste e naquele caso» (Carneiro 2003, 119).

Ao pensarmos as conquistas das mulheres na sociedade brasileira, necessitamos considerar percursos históricos diferentes, uma vez que as condições de vida femininas já partiam de patamares desiguais. Trata-se, porém, de considerar a interseccionalidade, ou seja, «a mulher negra continua vivendo em uma situação marcada pela dupla discriminação: ser mulher em uma sociedade machista e ser negra numa sociedade racista» (Munanga e Gomes 2006, 133).

Para Crenshaw (2012), que sistematizou conceitualmente a categoria interseccionalidade na década de 1990, é fundamental que as experiências das mulheres negras sejam consideradas a partir das categorias da discriminação racial e de gênero, posto que as interseções de ambas compactam e impactam sobre elas.

De acordo com Santos $(2016,18)$, 
o conceito de interseccionalidade, muito caro para a teoria do feminismo negro, recusa análises aritméticas sobre a articulação entre diferentes sistemas de opressão como gênero, classe e raça e busca compreender como a interação entre esses diferentes fatores particulariza a forma como determinados grupos vivenciam as desigualdades. (Santos 2016, 18)

Em concordância sobre a necessidade de especificar as diferenças entre mulheres, Rodrigues (2013) acrescenta a importância do termo interseccionalidade, que foi difundido por feministas negras na década de $1980^{2}$ e buscava integrar justamente diversas categorias que unificam ou diferenciam os grupos de mulheres dentro do contexto social. O termo foi muito utilizado, por exemplo, para que se considerassem três categorias principais em conjunto: classe, gênero e raça. Antes disso, questões de raça e gênero eram tratadas separadamente. Foi necessário «enegrecer» a luta feminista e «sexualizar» a luta do movimento negro, ou, conforme Biroli e Miguel (2015), a noção de interseccionalidade permite compreender que os sistemas de dominação são múltiplos. ${ }^{3}$

Nepomuceno (2012) assevera que, na virada do século XIX para o XX, as mulheres de boa parte do mundo e também do Brasil alçaram voos antes não imaginados. Conseguiram cargos que eram unicamente masculinos, conquistaram o direito ao voto e obtenção de diplomas. No entanto, essa trajetória de aquisições não se aplicou da mesma maneira a todas as mulheres, como é o caso das mulheres negras.

A raiz dessa desigualdade já aparecia no Brasil pós-abolição, onde mulheres negras trabalhavam como pequenas sitiantes, agricultoras e ambulantes de rua. $\mathrm{O}$ espaço de atuação delas não era o privado como as «bem-nascidas» e brancas, pois precisavam trabalhar pesado, visto que não existiu uma política justa de inserção no mercado após a libertação da escravatura (Nepomuceno, 2012; Munanga e Gomes 2006).

As raízes da desigualdade, vistas já no período de pós-abolição, se perpetuam até os tempos atuais, tanto pela dominação simbólica que acabou sendo

2 Conforme Santos $(2016,17)$, a corrente teórica que discute a interseccionalidade não surge como muitos autores indicam nos anos de 1980, segundo a autora: »surgiu na metade do século XIX, quando Sojourner Truth (1797-1883), que é definida como a pioneira da teoria do feminismo negro norte-americano, proferiu o discurso Ain't I A Woman? na Conferência dos Direitos da Mulher de Ohio em 1852».

3 Raça é entendida como construção política e social. Uma categoria «discursiva em torno da qual se organiza um sistema de poder socioeconômico, de exploração e exclusão - ou seja, o racismo» (Hall 2003, 69). Cabe ressaltar que, conforme Gomes (2012), «a raça é ressignificada pelos sujeitos em suas experiências sociais. No Brasil, o movimento negro ressignifica e politiza afirmativamente a ideia de raça, entendendo-a como potência de emancipação e não como como uma regulação conservadora. [...] Ao ressignificar a raça o movimento negro indaga a própria história do Brasil» (Gomes 2012, 731). 
naturalizada, como destaca Bourdieu (2002), como pelo facto de aumentar o distanciamento social entre mulheres negras e brancas.

Conforme Reichmann (1995), essas divisões foram mantidas na medida em que ocorreu uma separação até mesmo física desses núcleos, visto que os negros foram retirados das cidades para morar em regiões afastadas da área urbana. Logo, os negros, além de discriminação racial, sofreram pela pobreza que se estabeleceu a partir disso e pelo acesso escasso ao ensino, já que - separados por um abismo social - tinham mais dificuldades em manter os filhos em boas escolas ou precisavam, ainda jovens, abandonar os estudos para ajudar nas despesas da casa.

A autora ressalta ainda que apesar do discurso oficial defender uma «identidade brasileira suprarracial ignorando o status marginal da vasta população negra, os negros brasileiros [...] continuaram a sofrer discriminação» (Reichmann 1995, 496).

De acordo com a autora, as mulheres negras são marginalizadas duplamente, pois, embora a participação delas no emprego industrial no Brasil tenha mais do que triplicado desde 1970, sempre ganharam um salário menor do que o dos homens e do que o de outras mulheres não negras.

Com a discriminação racial e de gênero, as mulheres começaram a unir suas forças para reivindicar seus direitos na sociedade. Houve o ressurgimento de movimentos sociais na década de 1970, em plena ditadura civil-militar. Nesse período, os movimentos do feminismo e do negro ressurgem, tendo como eixos básicos a luta pela democracia e o fim da desigualdade. No entanto, nos dois campos as mulheres negras aparecem como sujeitos implícitos (Ribeiro 1995).

Ribeiro (1995) afirma que as mulheres negras participantes dos movimentos negros e feministas buscaram desmascarar as situações de conflito e exclusão que sofriam pelas suas condições de serem mulheres e negras. O movimento contemporâneo de mulheres negras emergiu no bojo da luta feminista e antirracista da década de 1970. No entanto, foi constatada uma presença mais organizada das mulheres negras no movimento feminista em proporção nacional e continental apenas a partir de 1985.

Conforme Collins, «o termo Feminismo Negro desestabiliza o racismo inerente ao apresentar o feminismo como uma ideologia e um movimento político somente para brancos» $(2017,12)$. Para a autora, é importante perceber que o uso do termo feminismo negro envolve «várias dificuldades», sendo uma delas «equilibrar as preocupações genuínas de mulheres negras contra as pressões contínuas para absorver e reformular interesses no âmbito das estruturas feministas brancas» (Collins 2017, 15).

No Brasil, registrou-se o surgimento do Instituto da Mulher Negra (Geledés), em 1988, que permanece até hoje como um dos grupos mais importantes no cenário nacional. O grupo vem consolidando as discussões sobre a problemática da mulher negra como aspecto fundamental da temática de gênero na sociedade bra- 
sileira e impulsionando o debate sobre a necessidade de adoção de políticas públicas inclusivas para a realização do princípio de igualdade de oportunidades para todos (Geledés 2016).

Nesse mesmo período, o movimento feminista traz para o campo político questões consideradas da vida particular e privada, como a sexualidade livre, orientação sexual, creches, relações familiares e também questões como igualdade salarial, acesso profissional, políticas públicas de gênero e representação no campo da política. Já o movimento negro reivindica melhores condições de vida e denuncia o racismo, protestando também contra a dificuldade de inserção no mercado de trabalho e a violência policial (Ribeiro 1995).

Segundo Ribeiro, «o racismo constitui uma sintomática que caracteriza a neurose cultural brasileira [...] sua articulação com o sexismo produz efeitos de violência sobre a mulher negra» $(1995,447)$. A autora conclui que as mulheres negras são vistas como cidadãs de segunda categoria e lamenta o facto de terem que, muitas vezes, lutar sozinhas, pois «até hoje entre nós feministas no Brasil a questão racial tem geralmente ficado a cargo das mulheres pretas como se apenas elas fossem marcadas pela raça» (Ribeiro 1995, 448).

Caldwell assevera que o facto de as mulheres negras constituírem minoria nas universidades brasileiras tem dificultado o desenvolvimento da pesquisa acadêmica sobre a mulher negra. Sendo assim, segundo a autora, «maior parte da pesquisa sobre mulher continua a retratar as mulheres brasileiras em termos monolíticos e não lida com o significado de raça na vida das mulheres, negras ou brancas» $(2000,5)$.

A autora destaca que no ano de 1975 o Manifesto das Mulheres Negras, apresentado no Congresso de Mulheres Brasileiras, foi marcado pelo «reconhecimento formal de divisões raciais dentro do movimento feminista brasileiro» (Caldwell 2000, 7). O ano foi marcado pela mobilização do movimento feminista brasileiro, mas também pelo manifesto que colocou em relevo as especificidades das identidades sociais das mulheres negras, bem como a presença marcante da dominação racial (Caldwell 2000, 6).

Para Fernandes e Souza, «o racismo dificulta o diálogo entre os diferentes grupos que compõe a sociedade brasileira, pois cria fronteiras simbólicas rígidas» $(2016,106)$, respaldando uma construção de oposição do ser branco e do ser negro, baseada em estereótipos positivos e negativos, respectivamente. Neste sentido, o racismo nega a alteridade da população negra, vinculando-a a inferioridade e maldade.

Considerando a intersecção de categorias - raça e gênero -, pontua-se que as mulheres negras brasileiras ainda ocupam um lugar de menor visibilidade na sociedade, não somente pelos factos mencionados até o momento, como salários menores e profissões de menos prestígio, mas também pelo poder simbólico constituído ao longo dos anos, os quais podemos ver na baixa representatividade midiática, por exemplo. Ademais, conforme demonstra o Mapa da Violência de 
2015, são as mulheres negras as principais vítimas de violência contra a mulher, onde ocupam altos índices de abusos sexuais e violência física. ${ }^{4}$

Cabe ainda destacar, a partir do enfoque interseccional que as questões de raça e gênero e os conflitos latentes na formação social brasileira são expressas na figura da mulata, constituída no nível simbólico nacional como a dengosa, graciosa, sensual. A mulata é vista como a desejável que provoca descenso social, enquanto o mulato simboliza ascensão social ou desafio à ordem social. De acordo com Correa, a literatura nacional corrobora com a constituição de uma imagem positiva do homem mulato e negativa da mulher mulata. Para Caldwell, a «herança cruel que coube às negras do Brasil, lembrando o cruzamento das raças durante a época colonial resultou na mulata - considerada o único produto brasileiro que merece exportação» (Caldwell 2000, 8).

Conforme Giacomini,

a mulata se engaja em um tipo de mediação/comunicação bastante distante do modelo de mulher que viabiliza, como signo, através do casamento e das identidades de esposa e mãe, a aliança entre duas famílias. A mulata não se apresenta como um valor por referência ao grupo familiar - filha, irmã - que irá funcionar como valor-signo na mediação entre famílias, mas, ao contrário, como mulher sem família, exposta, disponível, cujo valor advém exclusivamente da sexualidade. (Giacomini 1994, 220)

A «harmonia racial» presente na construção simbólica da mulata irresistível a partir do olhar do homem branco «esconde e inverte a relação de dominação a que esteve submetida a mulher negra: enquanto escrava e enquanto mulher» (Giacomini 1994, 223). Nesta perspectiva, pensar acerca das mulheres negras é refletir sobre as relações de poder presentes nas relações raciais e de gênero constituídas em uma sociedade sexista e racista.

\section{Moda, corpo e o espaço social}

O corpo interfere no espaço social, uma vez que até mesmo o mercado de trabalho pode exigir certo "padrão de beleza». Isso diz muito sobre a importância do corpo na contemporaneidade: passa a ser um valor, um bem, no sentido de propriedade.

Para Rodrigues, «o corpo é sempre uma representação da sociedade» (1979, 129), já que como parte do comportamento social humano, o corpo é um facto social e um complexo de símbolos.

Todo o retrato da desigualdade por gênero e raça pode ser acessado em $<$ http://www.ipea.gov. br/retrato/>. 
Ao falarmos de corpo como facto social e como representação, cabe lembrar que o corpo da mulher negra (assim como o da mulher indígena) foi alvo de «uma violência sexual sistemática durante o contexto colonial das Américas» (Santos 2016, 16). Neste sentido, ao pensarmos sobre o corpo negro, se faz necessário pensar na sua relação com a construção histórica racial e sexista, bem como de enfrentamentos de conflitos e abusos que permearam (e permeiam) as experiências das mulheres negras em seu cotidiano.

Não obstante, assim como o corpo, a moda faz parte da diferenciação social. Takahashi (2007) salienta que a indústria da moda se sustenta da imagem do corpo e, como imagem, a moda comunica. Na mesma perspectiva, Oliveira e Castilho (2008) defendem que a moda e o corpo são referenciais básicos do sujeito contemporâneo e participam das construções sociais e identitárias de indivíduos e grupos.

Gardin (2008) traz para discussão o corpo e a moda na mídia, uma vez que o corpo foi o primeiro veículo de comunicação e expressão utilizado pela humanidade. Hoje, segundo o pesquisador, isso é o que mais se explora nas representações midiáticas, uma vez que pela mídia se perpetuam os padrões «ideais». O autor ainda salienta que «criou-se o corpo perfeito para desfilar a roupa» (Gardin $2008,75)$. Mas, antes que se tenha uma imagem da moda apenas como ditadora de beleza, o autor pondera que as roupas também servem para unir o sujeito à sua «tribo» - seja ela qual for--, pois, ao aderir a determinado código de vestimenta, ele «adere aos valores sociais, políticos, filosóficos e estéticos dessa classe» (Idem, 76).

Já se pode perceber o poder de coletividade da moda. Vestir ultrapassa a aparência e alcança valores culturais unificadores de grupos.

Nesse sentido, Crane (2006) aborda diversos momentos históricos em que a moda marcou mudanças mundiais em processos de unificações e diferenciações. Dentre as diferenças pontuadas pela autora, destaca-se a diferenciação por classe social e por gênero que nos séculos passados era muito definida pela indumentária. A autora ainda sublinha questões importantes como identidades regionais e religião, formas que também foram - e ainda são, em alguns locais - expressas a partir do vestuário.

A mesma autora assevera que «as roupas, como artefatos, criam comportamentos por sua capacidade de impor identidades sociais e permitir que as pessoas afirmem suas identidades sociais latentes» (Crane 2006, 22). Exemplo dessa afirmação é o facto da masculinização do feminino por mulheres que começaram a ocupar funções masculinas na sociedade em meados do século XIX, por exemplo. Já existiam comportamentos desviantes provenientes de mulheres que se apropriavam de artefatos como gravatas para a composição de suas vestes.

Crane (2006) sublinha que as diferenças por meio das vestes eram mais percebidas antes da revolução industrial. Hoje, segundo a autora, encontramo-nos no momento pós-industrial ou pós-moderno em que cada vez menos essas diferenças são percebidas a partir de classe e gênero, aparecendo muito mais questões identi- 
tárias e unificações de grupos sociais. Passou-se, portanto, de uma moda regida pela classe para uma moda regida pelo consumo.

Dessa maneira, percebemos que a moda, em conjunto com o corpo - visto que pele e tecido podem ser vistas como extensões do sujeito -, há muito tem o papel de classificar, diferenciar e colocar os sujeitos em determinados lugares e condições.

Pensar corpo e moda é pensar, também, a sociedade e o percurso histórico da humanidade. Claro que os modos de classificação mudaram ao longo do tempo e hoje há muito mais liberdade para que o sujeito escolha e comunique seu estilo. Dessa maneira, fica ainda mais pertinente pensarmos a moda como uma ferramenta de ação e comunicação social. E um dos mecanismos que as mulheres negras utilizam para ressignificar suas representações culturais é a «manipulação do corpo, se constituindo como mecanismo de aceitação/rejeição individual (identidade interna), seja este estabelecido para expressão coletiva (identidade externa), seja este estabelecido para expressão coletiva» (Oliveira 2011, 125).

A moda não apenas veste, mas fala, afirma e contesta. Moda e corpo são ferramentas de ação. E são essas ações que procuramos discutir nas páginas da Revista Raça/Afro Brasil.

\section{A moda militante}

A partir da leitura das revistas, organizamos as nossas análises em dois eixos temáticos: vestuário e editoriais de moda e cabelos. Neles priorizamos as falas e imagens de mulheres, procurando sempre relacionar com o percurso histórico e percebendo, nessas falas, desejos e reivindicações sociais e culturais, quer como mulheres, quer como negras.

Na temática sobre vestuário e editoriais de moda, destacamos algumas matérias pontuais de caráter afirmativo que apresentaram a cultura afro. Adornos como o turbante ganharam grande destaque na revista. Este acessório, comparado pela revista a uma coroa - em matéria intitulada «Meu turbante, minha coroa!», demonstra a importância cultural que ele tem.

Há nele um significado religioso e político relacionado à ancestralidade do povo negro. Usá-lo é uma ferramenta de afirmação étnica e política. Na edição com o número 2, aparece novamente uma matéria sobre o acessório, reiterando a peça como constituinte da identidade cultural de um povo. Conforme pode-se observar na figura a seguir: 
Figura 1.

Turbantes
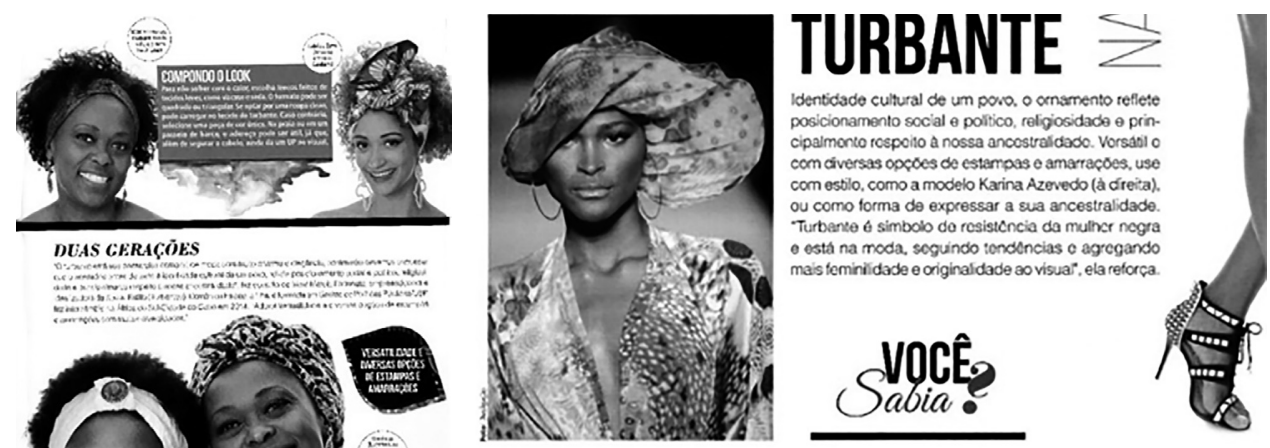

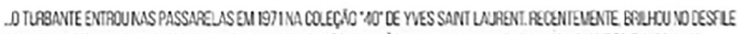

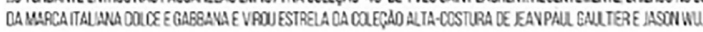

GSINROM

Fonte: Recortes de Raça Brasil, n. ${ }^{\circ} 198$ (2016), e Afro Brasil, n. ${ }^{\circ} 2$ (2016).

Souza dedicou-se a relatar os rituais, os mitos e a estética do candomblé, nesse sentido, aponta que «o torço, ou turbante, é uma peça muito importante do vestuário afro-brasileiro de origem árabe, como muitas outras do vestuário africano e afro-brasileiro, que originalmente tinha a função de proteger a cabeça do sol» $(2007,57)$.

Além do significado ritualístico, a peça é usada por homens e mulheres no dia a dia como utilitário para manter os cabelos presos. Seu uso ainda pode ser relacionado a um tempo em que o negro sentia a necessidade de esconder o «cabelo ruim» (Souza 2007), pois se sentia desprezado pela dominação dos brancos.

Dessa maneira, não há dúvida de que a peça tem uma íntima relação cultural aqui no Brasil, marcando a ancestralidade do povo africano e sendo utilizado até hoje nos rituais religiosos. Nesse sentido, a peça também causa preconceitos, como é o caso relatado por Silva (2007), que afirma que qualquer traço de herança africana ou que aluda às religiões afro-brasileiras é estigmatizado e combatido no meio social por algumas pessoas que não aceitam religiões fora da «normativa».

As imagens de mulheres nessas colunas que têm o turbante como foco, portanto, representam a articulação entre luta e afirmação política diante de uma sociedade que ainda condena elementos ritualísticos e símbolos da figura negra.

Nessa mesma perspectiva cultural, outras características foram percebidas nos vestuários. Culturas de rua e músicas populares como o Hip Hop e samba também aparecem como grandes influenciadores de moda. Conforme editoriais a seguir: 
Figura 2.

Editoriais de Moda

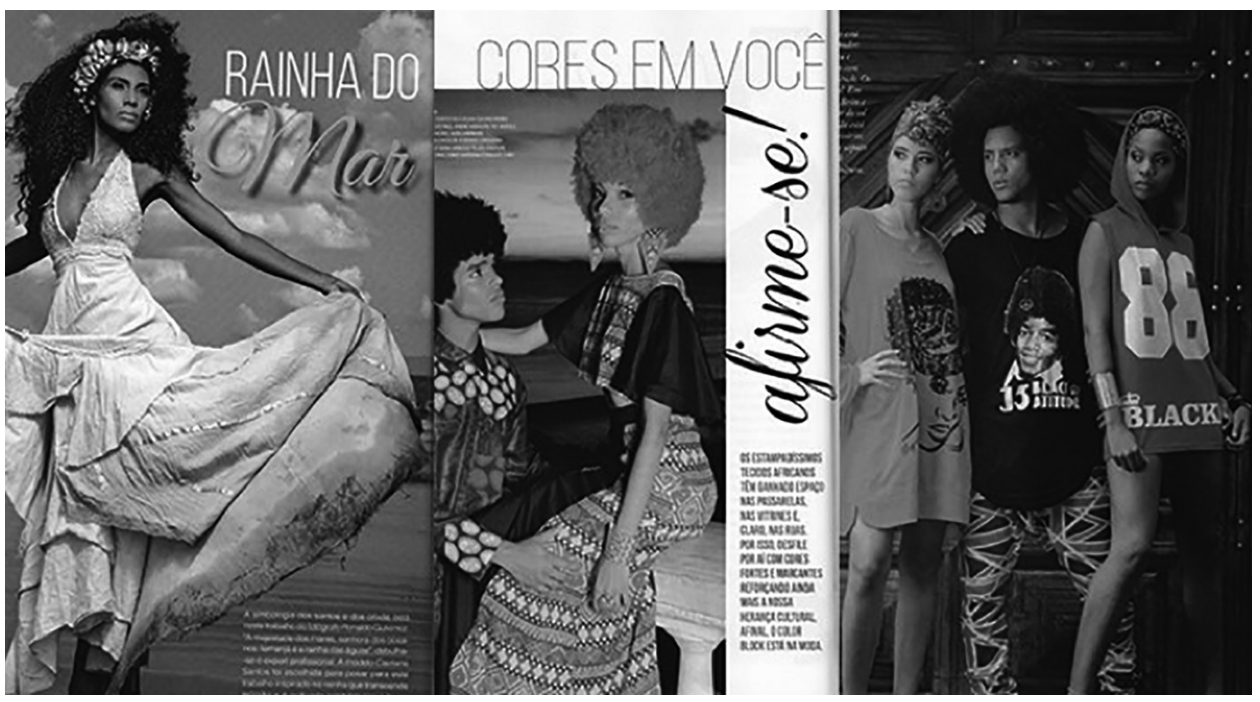

Fonte: Revista Afro Brasil, n. ${ }^{\circ} 2$ (2016)

À esquerda da figura 2, percebe-se forte influência da cantora Clara Nunes, famosa sambista nacional, bem como uma referência à Iemanjá, divindade de forte presença em religiões africanas. Segundo Souza (2007), representar a figura de Iemanjá requere conhecimento de causa, como por exemplo, saber que cores agradam a divindade.

Nesse sentido, a revista respeita o uso de cores claras, bem como os apetrechos ligados ao mar. A foto, de perto, faz jus aos detalhes: conchas, pedras na cor azul relacionada com a cor do mar estão presentes na tiara utilizada pela modelo. A pose, igualmente majestosa, pode remeter à divindade de uma mulher, a rainha das águas. Além disso, a modelo também lembra a figura de Clara Nunes, que além de figura importante na cena musical brasileira, possuía uma estreita ligação religiosa com a Umbanda (Bakke 2007).

Nessa mesma perspectiva de valorização cultural, percebemos frases com alto teor afirmativo que aparecem em diversos editoriais de moda, onde há um cruzamento de diversas fontes de inspiração étnica, como estampas de traços africanos e as belezas das modelos contemplando o black-power, assim como elementos do hip hop e outros.

À direita da figura 2, vemos a ordem «Afirme-se!», seguida de modelos com muitas cores e estampas. À extrema direita da figura, uma alusão ao gênero musical é destaque, pois, segundo Matsunaga (2006), passou a existir uma «estética do hip hop», basicamente montada por roupas mais largas, bonés, camisetas com frases e jaquetas grandes. 
Outro fator de destaque que gostaríamos de trazer à tona é que a maioria das modelos, embora quebrem padrões da normatividade branca, ainda seguem alguns padrões estéticos bem específicos. Não vemos, por exemplo, pelo menos nessas colunas de editoriais de moda, mulheres mais velhas, gordas ou que fujam de características ditas «femininas». Não há sinais de quebra de padrões de gênero, de modo que mulheres negras que se enquadram na comunidade LGBTQ+ ${ }^{5}$ podem não se encontrar contempladas.

Para não dizer que não há nenhuma quebra nesses padrões, há de se mencionar que a revista, com o novo nome Afro Brasil, traz uma coluna plus size - especial para mulheres que rompem os padrões de magreza. Consideramos um passo importante para a inclusão de corpos e mulheres reais, no entanto, ainda é uma coluna à parte, de modo que não vemos essas mulheres misturadas aos editoriais de moda praia, por exemplo.

O eixo temático intitulado «cabelos» talvez tenha sido o que mais nos chamou a atenção, por estar «em transição» junto com o nome da revista, ou seja, apareceu em praticamente todas as matérias analisadas o termo «transição capilar», isso é, a retomada dos cachos que foram durante anos alisados artificialmente. Gilliam e Gilliam (1995), ao mencionar a relação dos negros e negras com o cabelo, apontam seus diferentes significados, mas ressaltam que «décadas depois do fim do sistema escravagista a posição social e a mobilidade ficam presas ao sistema de códigos fisiológicos» $(1995,533)$.

No exemplar 197, nos deparamos com a seguinte frase: «Os fios encaracolados são uma realidade para a mulher brasileira, por isso, chegou a hora de assumir seus cachos» (Raça Brasil 2015, 60). Não por mera coincidência, mas as questões da estética dos fios têm sido vistas em gritos uníssonos do feminismo negro atual, tanto que há uma marcha recente chamada «Orgulho Crespo» (ver foto, Fig. 3).

Assim como o turbante tem se mostrado uma ferramenta de afirmação, o mesmo ocorre com o cabelo. Frisa-se, no entanto, que não é um movimento de transição homogêneo: há quem opte pela mudança e há quem opte pelo alisamento sob a justificativa de que é mais fácil de manter, de cuidar e de arrumar.

Entendemos a sociedade atual assim como Bauman (2013) e Hall (2006) pontuam: as identidades são transitórias e também somos influenciados por tendências globais. Logo, alisar o cabelo nem sempre é um ato de «negar» as origens e sim uma opção como qualquer outra, como pintar de rosa, de azul e ter a liberdade de se reinventar. Os cabelos crespos são marcadores étnicos muito significativos, e sua manipulação é um mecanismo pelo qual «as representações culturais das mulheres negras são reproduzidas ou mesmo ressignificadas» (Oliveira 2011, 117).

Sigla: Lésbicas, Gays, Bissexuais, Transsexuais, Queer e mais. 
Figura 3.

Marcha do orgulho crespo em São Paulo

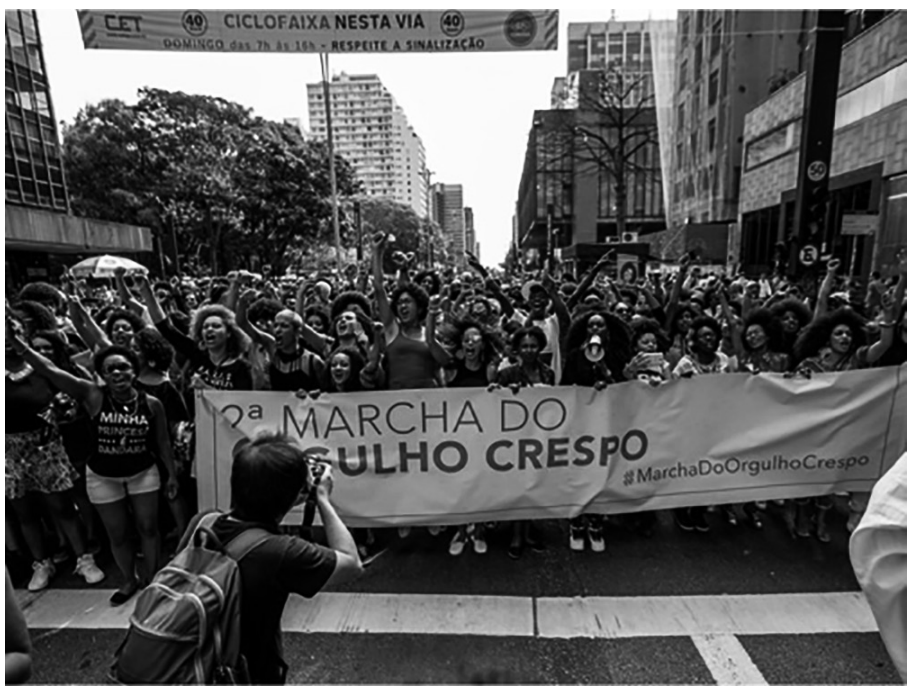

Fonte: $\mathrm{G1}, 2016^{6}$

Neste sentido, cabe destacar que a categoria negra (negro) e corpo negro não podem ser pensadas de forma homogênea, desconsiderando a diversidade e a complexidade social, histórica e cultural que envolve a construção de tais categorias. Assumir os cabelos crespos como um marcador social é uma forma de se contrapor ao paradigma da inferioridade, do ruim, do historicamente negativo constructo social no Brasil através de práticas discursivas de padrões culturais de superioridade e universalidade eurocêntricos (Fernandes e Souza 2016, 109).

No entanto, esse movimento de aceitação e transição existe porque boa parcela hoje - e cada vez mais - se dá conta dos padrões impostos. Xavier (2013) aponta questões sobre a noção construída da «boa aparência» negra. Para tanto, ela verifica o início dessa construção no período do pós-abolição, focando seus objetos de pesquisa no início do século XX. A autora traz um compilado de anúncios dos Estados Unidos e do Brasil e percebe um discurso muito similar, no qual eram incentivadas características do «meio negro». Ou seja: uma pele nem tão escura e um cabelo nem tão crespo.

Podemos perceber que os cosméticos vinham para «atenuar» as características africanas. As mulheres negras recorriam a essas estratégias porque quanto mais se assemelhassem às brancas mais respeito teriam no espaço público. Foi

Disponível em: <http:/g1.globo.com/sao-paulo/noticia/2016/08/mulheres-participam-da-2-marcha-do-orgulho-crespo-em-sao-paulo.html>. Acesso em: $20 \mathrm{dez} .2016$ 
uma maneira de distinção, de deixar para trás os traços da escravidão em um processo longo que, aos poucos, foi se naturalizando e parecendo «errado» ou «feio» carregar suas origens africanas. O termo beleza cívica que a autora menciona é ainda mais forte, pois, se pararmos para pensar o contrário, a beleza originalmente negra seria entendida como algo a não ser aceito, logo contribui para o estigma negativo que se tem a partir dos traços negros. Justifica-se, assim, a estética como «capital social crucial» (Xavier 2013) para que as mulheres negras fossem respeitadas - ou se sentissem assim.

A partir daí uma ideia de «cabelo ruim» (relacionado aos crespos) ou «cabelo bom» (aos alisados) foi se constituindo no imaginário coletivo, o que imperou por muito tempo. Quem acabava assumindo seus cabelos podia passar por situações de discriminação e preconceito, afinal, o bonito e feio são ensinados e construídos como os demais julgamentos que se dão a partir de diferenças. Esse desejo de fazer com que mulheres negras, leitoras da revista se sintam bem com sua imagem fica bastante explícito na seguinte matéria:

Figura 4.

De bem com o espelho

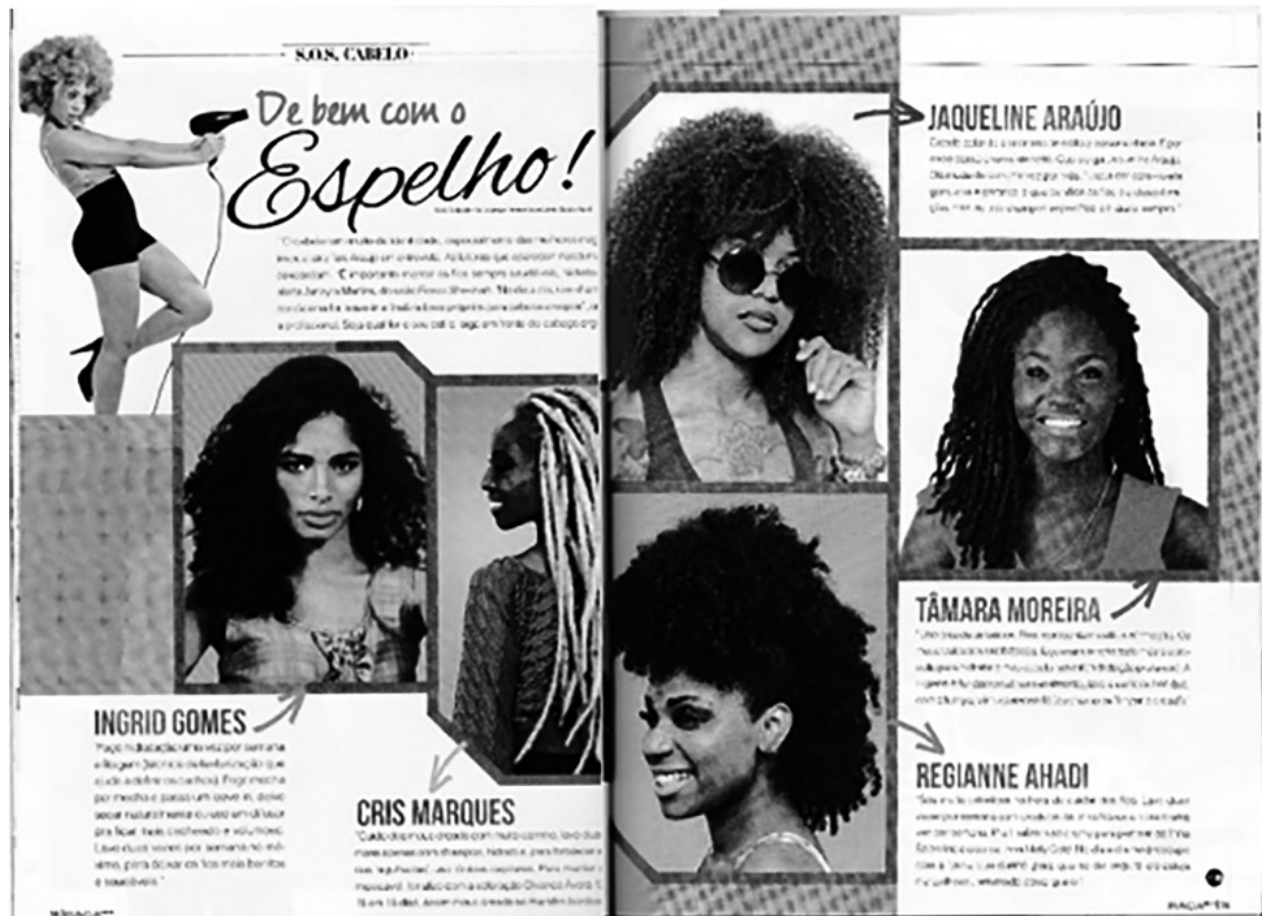

Fonte: Revista Raça Brasil, n. ${ }^{\circ} 198$ (2016). 
Ao mencionar «de bem com o espelho» (figura 4), podemos ter uma ideia de convite a fazer as pazes consigo mesma. Aceitação e dicas para cuidados dos fios aparecem em todo o decorrer da matéria e as entrevistadas dizem que assumiram seus cachos e dreads por motivos de afirmação e orgulho da etnia, socializando com suas leitoras produtos preferidos para tratar dos fios e alguns segredos de beleza.

No entanto, embora a revista traga essa questão afirmativa e de orgulho dos cachos muito forte, não deixa de contemplar a liberdade de se fazer o que se quer com os cabelos. Há matérias que exploram tinturas, penteados como tranças, cortes bem curtinhos e, até, dicas para aquelas que optam por continuar com seus cabelos alisados - demonstrando que a revista se posiciona democrática e respeitosamente com suas leitoras que têm total liberdade com seus modos de expressão e suas aparências.

A revista, através das matérias e produtos ofertados, se inscreve em uma lógica capitalista, mas revestida de significados e representações culturais, as quais buscam estar em consonância com o debate das questões étnico-raciais dedicando um espaço midiático para negras e negros e corroborando em uma positivação da negritude com suas diferentes faces.

\section{Considerações finais}

O jornal Folha de S. Paulo apontava em 2007 que a revista Raça Brasil tinha tido um sucesso enorme no lançamento «mas que, com o tempo, acabou sendo exibida nas seções femininas das bancas de revista». Tal frase dá a entender que indo para uma seção feminina, a revista poderia perder seu prestígio inicial como aquilo que a deixou conhecida: a primeira revista dos negros brasileiros.

Gostaríamos de fazer uma provocação: não seria exatamente esse um caminho possível e efetivo de mudança? Ir para a seção feminina assuntos tão pertinentes à luta da mulher negra como autoafirmação, orgulho e superação talvez seja realmente um modo eficaz de ação política. Ou melhor, a revista se torna uma ferramenta para leitoras de diversas idades que podem incorporar um discurso por anos negligenciado pela mídia, rompendo padrões normativos que deixam de lado as múltiplas mulheres brasileiras. Talvez a seção feminina - de onde se espera futilidade e obediência já que historicamente é isso que atribuem insistentemente às mulheres -, tem se tornado política.

Mas como essas mulheres se colocam politicamente? Pois bem, o corpo também fala. A maneira como nos apresentamos para o mundo é um modo de comunicação e interação com o meio social. É estar, é ser e é falar, sem necessariamente usar a voz. Sim, queremos passar um recado com a nossa imagem, ainda que seja uma mensagem «inconsciente». Mas não aqui. Aqui o recado foi se mostrando claro e bastante consciente durante todo o percurso analítico. Não há nada de vazio no discurso das páginas da revista Raça/Afro Brasil. Pelo contrário, o 
periódico se mostrou muito rico para se pensar na proximidade da moda com o feminismo negro.

Vimos que, ao longo do cenário histórico brasileiro, aos negros e às mulheres foram atribuídos valores negativos. Os negros, que sofreram as consequências de uma pós-abolição sem nenhuma estratégia de inserção justa na sociedade, já começaram sua história no Brasil em patamares desiguais. As mulheres também. Até alcançarem o espaço externo, foi preciso muita luta e empenho do feminismo, que buscava e ainda busca direitos igualitários e justos. A partir da linha teórica do feminismo interseccional, foi preciso pensar a mulher como uma categoria não homogênea. Ser mulher e negra é diferente de ser «simplesmente» mulher em diversos aspectos. Assim, estabelece-se uma dupla discriminação que resulta em mais desigualdades sociais.

As mulheres negras brasileiras ainda possuem menor média de renda, menor representatividade política e menor acesso ao ensino superior. Em contrapartida, ela ganha em disparada em outros aspectos, como é o caso da violência doméstica. Se não bastasse, além de todas essas desigualdades quantitativas, há o estigma com o qual essas mulheres têm de conviver ao longo dos anos. Como vimos, instalou-se uma normatividade excludente quando se trata da tal «boa aparência». Além, claro, de serem representadas ainda como mulheres de uma categoria inferior que as outras, basta olharmos filmes, novelas e campanhas publicitárias brasileiras, que deixam claro quais são as representações culturais das mulheres negras no Brasil.

Ainda que tenhamos uma legislação que criminaliza o racismo e o sexismo e leis de incentivo à cultura afro-brasileira, continuamos presenciando casos de racismo e casos de extrema violência contra mulheres negras, além do inegável abismo social que ainda separa sujeitos por raça e gênero.

Portanto, a revista, por meio das colunas de moda e beleza - assuntos relacionados insistentemente à figura feminina -, está indo a lugares aonde a lei não tem conseguido chegar: nas subjetividades. Não estamos dizendo que é a solução. Mas estamos afirmando que é uma forma de ação social. Trabalhar com representações positivas da mulher negra (em editoriais de moda, em afirmação de cabelos crespos, por exemplo) contribui para a desconstrução da imagem negativa que foi construída ao longo dos anos. Trabalhar com subjetividades é acionar intimamente a cultura de um povo. Ou seja, é questionar e desmistificar algumas «certezas».

Há, nesse sentido, uma mudança social, de comportamento, de combatividade e de aparências. Estão colocando de volta suas coroas (turbantes!), estão trazendo para a moda elementos do rap, hip hop, de religiões de vertente africana. Estão se apossando daquilo que lhes é de direito: suas manifestações culturais.

Acreditamos, nesse sentido, que a pauta do feminismo negro, que luta pelo reconhecimento e pelo protagonismo que há anos foi ignorado, é também falar sobre representações positivas. É falar de moda, é falar de estética. A moda, citando e concordando com o estilista Ronaldo Fraga, é política. 


\section{Referências bibliográficas}

Afro Brasil. 2016. Edição 2. Editora Minuano.

Bakke, Rachel Rua Baptista. 2007. «Tem orixá no samba: Clara Nunes e a presença do candomblé e da umbanda na música popular brasileira». Religião \& Sociedade 27 (2): 85-113. DOI: https://doi.org/10.1590/S0100-85872007000200005

Bauman, Zygmunt. 2013. A cultura no mundo líquido moderno. Rio de Janeiro: Zahar.

Biroli, Flávia, e Luis Felipe Miguel. 2015. «Gênero, raça, classe: opressões cruzadas e cconvergências na reprodução das desigualdades». Mediações - Revista de Ciências Sociais, v.20, n.2, jul/dez. DOI: 10.5433/2176-6665.2015v20n2p27

Bourdieu, Pierre. 2002. A dominação masculina. 2. ${ }^{a}$ ed. Rio de Janeiro: Bertrand Brasil.

Caldwell, Kia Lilly. 2000. «Fronteiras da diferença: raça e mulher no Brasil». Estudos Feministas 8 (2): 91-108. Disponível em https://www.jstor.org/stable/43596552

Carneiro, Sueli. 2003. «Mulheres em movimento». Estudos Avançados 17 (49): 117-132. DOI: https://doi.org/10.1590/S0103-40142003000300008

Crenshaw, Kimberlé. 2012. A intersecionalidade na discriminação da raça e gênero. Painel ICruzamento Raça e Gênero, 7-16. Disponível em http://www.acaoeducativa.org.br/fdh/ wp-content/uploads/2012/09/Kimberle-Crenshaw.pdf

Collins, Patricia Hill. 2017. «O que é um nome? Mulherismo, feminismo negro e além disso». Cadernos Pagu 51: 1-24. DOI: https://doi.org/10.1590/18094449201700510018

Crane, Diana. 2006. A moda e seu papel social: classe, gênero e identidade das roupas. São Paulo: Senac.

Fernandes, Viviane B., e Maria Celia Cortez C. Souza. 2016. «Identidade Negra entre exclusão e liberdade». Revista do Instituto de Estudos Brasileiro 63: 103-120. DOI: https://doi. org/10.11606/issn.2316-901X.v0i63p103-120

Gardin, Carlos. 2008. «O Corpo Mídia: Modos e Moda». In Corpo e Moda: Por uma Compreensão Contemporânea, organizado por Ana Claudia de Oliveira e Kathia Castilho. Barueri: Estação das Letras e Cores Editora, 75-83.

Geledés. 2016. Disponível em http://www.geledes.org.br [Consultado em 21 de maio de 2016].

Giacomini, Sonia Maria. 1994. «Beleza mulata e beleza negra». Estudos Feministas 94 (N.E.) 217-226. Disponível em https://periodicos.ufsc.br/index.php/ref/article/view/16105

Gilliam, Angela, e Onik'a Gilliam. 1995. Negociando a subjetividade de mulata no Brasil. Estudos Feministas 3 (2): 525-543. Disponível em https://periodicos.ufsc.br/index.php/ ref/article/view/16471

Gomes, Nilma L. 2012. «Movimento Negro e Educação: Ressignificando e Politizando a Raça». Educação \& Sociedade 33 (120): 727-744. DOI: https://doi.org/10.1590/S010173302012000300005

Hall, Stuart. 2003. Da diáspora. Identidades e Mediações Culturais. Belo Horizonte: UFMG/ Humanitas.

Hall, Stuart. 2006. A identidade cultural na pós-modernidade. Rio de Janeiro: DP\&A.

Matsunaga, Priscila Saemi. 2006. «Mulheres no hip hop: identidades e representações». Dissertação de mestrado, Faculdade de Educação. Universidade Estadual de Campinas, São Paulo.

Munanga, Kabengele, e Nilma Lino Gomes. 2006. O negro do Brasil de hoje. São Paulo: Global.

Nepomuceno, Bebel. 2012. «Mulheres negras: Protagonismo ignorado». In Nova História das Mulheres no Brasil, organizado por Carla B. Pinsky, e Joana Maria Pedro, 383-409. São Paulo: Contexto.

Oliveira, Josiane Silva de. 2011. «As representações culturais das mulheres negras no mer- 
cado consumidor brasileiro». Revista de Administração da UNIMEP. Piracicaba, v. 9, n. 2, mai/ago.

Oliveira, Ana Claudia, e Kathia Castilho. orgs. 2008. Corpo e moda: por uma compreensão do contemporâneo. São Paulo: Estação das Letras e Cores.

Raça Brasil. 2015. Edição 197. Editora Minuano.

Raça Brasil. 2016. Edição 198. Editora Minuano.

Reichmann, Rebecca. 1995. «Mulher negra brasileira um retrato». Revista Estudos Feministas 3 (2): 496-505. Disponível em https://periodicos.ufsc.br/index.php/ref/article/view/16468

Ribeiro, Matilde. 1995. «Mulheres negras brasileiras: de Bertioga a Beijing». Revista Estudos Feministas 3 (2): 446-457. Disponível em https://periodicos.ufsc.br/index.php/ref/article/view/16459

Rocha, José Geraldo. 2010. «De preto à afrodescendente: implicações terminológicas». Cadernos do CNLF XIV (4): 899-907. Disponível em http://www.filologia.org.br/xiv_cnlf/

Rodrigues, Cristiano. 2013. «Atualidade do conceito de interseccionalidade para a pesquisa e prática feminista no Brasil». Seminário Internacional Fazendo Gênero (Anais Eletrôni$\cos$ ), Florianópolis. Disponível em: https://poligen.polignu.org/sites/poligen.polignu. org/files/feminismo\%20negro2.pdf [Consultado em 3 de maio de 2015].

Rodrigues, José Carlos. 1979. Tabu do Corpo. Rio de Janeiro: Achimé.

Santos, Giselle Cristina dos Anjos. 2016. «Os estudos feministas e o racismo epistêmico». Revista Gênero 16 (2): 7-32. Disponível em http://www.revistagenero.uff.br/index.php/ revistagenero/article/view/812

Silva, Vagner Gonçalves. 2007. «Neopentecostalismo e religiões afro-brasileiras: Significados do ataque aos símbolos da herança religiosa africana no Brasil contemporâneo». Mana 13 (1): 207-236. DOI: https://doi.org/10.1590/S0104-93132007000100008

Soihet, Rachel, e Joana Maria Pedro. 2007. «A emergência da pesquisa da História das Mulheres e das Relações de Gênero». Revista Brasileira de História 27 (54): 281-300. DOI: https://doi.org/10.1590/S0102-01882007000200015

Souza, Patricia Ricardo. 2007. «Axós e Ilequês. Rito, Mito e a Estética do Candomblé». Tese de Doutorado em Sociologia. Universidade de São Paulo, São Paulo.

Takahashi, Jo. 2007. «Dimensões do corpo contemporâneo». In Leituras do corpo, organizado por Christine Greiner, e Cláudia Amorim. São Paulo: Annablume.

Xavier, Giovana. 2013. «Segredos de penteadeira: conversas transnacionais sobre raça, beleza e cidadania na imprensa negra pós-abolição do Brasil e dos EUA». Estudos históricos 26 (52): 429-450. DOI: https://doi.org/10.1590/S0103-21862013000200009

Larissa Adams Braga. Mestra em Processos e Manifestações Culturais, Bacharela em Moda pela Universidade Feevale, Brasil.

Endereço eletrónico: 1.adamsbraga@gmail.com

Magna Lima Magalhães. Doutora e mestra em História, professora e pesquisadora da Universidade Feevale, Brasil.

Endereço eletrónico: magna@feevale.br

Claudia Schemes. Doutora e mestra em História, professora e pesquisadora da Universidade Feevale, Brasil.

Endereço eletrónico: claudias@feevale.br

Artigo recebido a 2 de junho de 2018 e aceite para publicação a 1 de setembro de 2018. 